\title{
Dependency Status and Demand for Social Insurance: evidence from experiments and surveys*
}

\author{
John S. Ahlquist \\ John Hamman \\ Bradley M. Jones
}

September 16, 2015

\begin{abstract}
Current thinking on the origins and size of the welfare state often ignores household relations in which people may depend on others for income or have dependents themselves. The influence of "dependency status" on individuals' political preferences is unknown. We report results from a laboratory experiment designed to estimate the effect of dependency on preferences for policies that insure against labor market risk. Results indicate that 1) willingness to vote in favor of a social insurance policy is highly responsive to unemployment risk, 2) symmetric, mutual dependence is unrelated to support for insurance, but 3) asymmetric dependence (being dependent on someone else) increases support for social insurance. We connect our lab results to observational survey data and find similar relationships.
\end{abstract}

For over a decade now our thinking on the political economy of the welfare state has focused on labor market risks and social insurance policy (Hall and Soskice, 2001; Iversen and Soskice, 2001; Moene and Wallerstein, 2001, 2003). Citizens' preferences over various social insurance policies (unemployment, disability, retirement, etc.) are held to be a function of the

${ }^{*}$ John Ahlquist is Associate Professor in the School of Global Policy \& Strategy, UC San Diego; research associate in political economy, United States Studies Centre at the University of Sydney. 9500 Gilman Drive, MC 0519, La Jolla, CA 92093-0519 USA (jahlquist@ucsd.edu). John Hamman is Assistant Professor of Economics at Florida State University. 113 Collegiate Loop Tallahassee, FL 32306-2180 (jhamman@fsu.edu). Bradley M. Jones is a Ph.D. Candidate in the Department of Political Science at the University of Wisconsin, Madison. 1050 Bascom Mall, Madison, WI 53706 USA (bmjones3@wisc.edu). Versions of this paper were presented at the Centre for Experimental Social Sciences, Nuffield College, Oxford; Duke University; the University of Pennsylvania; the Experimental Politics Workshop at the University of Wisconsin; the 2013 meetings of the Economic Sciences Association and the 2013 and 2014 meetings of the Midwest Political Science Association. We acknowledge help from Patrick Hurley and Brian Mayhew. Pablo Beramendi, Lucy Goodhart, Guy Grossman, John Patty, Jonathan Renshon, David Rueda, Dustin Tingley, and Jonathan Woon offered useful comments. Research support provided by the University of Wisconsin Fall Competition award 130485 (John Ahlquist, PI) 
economic risks they face. Simultaneously, existing levels of social insurance affect workers' willingness to acquire particular types of skills that may be more prone to obsolescence.

In focusing on individuals alone, this literature pays little attention to the fact that most economic decisions, especially regarding risk and insurance, are made at the household level. ${ }^{1}$ Households in advanced economies of the OECD typically rely on one or two individuals who earn the majority of household income through participation in the formal labor market. These earners are mutually dependent on one another but they may also have others (children, elders, or disabled persons) who also depend on them. In single earner households there may be a second adult who refrains from entering into the labor market in order to provide household services. These individuals depend directly on their partners for money income yet they often care for other dependents and vote.

Major studies of public support for social insurance policies have failed to account for marital status, head of household, or the presence of children (or other dependents) in their models of public opinion (Iversen and Soskice, 2001; Nickelsburg and Timmons, 2012; Rehm, 2009, 2011; Scheve and Stasavage, 2006). This omission is particularly worrying given the growing behavioral economics literature examining how major life events, including marriage, child bearing, and aging can affect people's attitudes toward risky choices (Bellante and Green, 2004; Bertocchi et al., 2010; Drewianka, 2008; Sundn and Surette, 1998). The joint effect of labor market participation and marriage on risk acceptance is most pronounced among women (Bertocchi et al., 2010; Sundn and Surette, 1998).

In this paper, we take steps toward better understanding how these household interactions affect preferences for the cornerstone of the welfare state-insurance against job loss. We use a stylized laboratory setting to focus on a generic household relationship: dependency, either mutual or asymmetric. Our findings indicate that the willingness to vote in favor of a social insurance policy is responsive to unemployment risk and one's asymmetric dependence on another for income. We then show that our lab findings are also visible in survey data.

\section{The Political Economy of Social Insurance}

\subsection{Redistribution and insurance}

There is a large body of theoretical and empirical work looking at the demand for both direct income redistribution and socialized insurance. ${ }^{2}$ Purely redistributive policies involve taxing a population (or some subset) and then distributing proceeds such that some are necessarily net beneficiaries and others are necessarily net contributors. Under canonical models of redistribution (e.g., Meltzer and Richard (1981)), the tax and distribution rules are known and agents anticipate whether they will be net beneficiaries, inducing preferences over tax rates and spending levels. Social insurance policies, on the other hand, are policies that mandate contributions in order to insure against specific risks. At the time of tax assessment agents do not know whether they will be (net) beneficiaries; there is some fundamental

\footnotetext{
${ }^{1}$ Iversen and Rosenbluth $(2006,2010)$ and Margalit (2013) are notable exceptions.

${ }^{2}$ See McCarty and Pontusson (2011) for a recent review.
} 
uncertainty against which the program is meant to insure. In canonical models contributions to the social insurance program are universal.

Scholars make an analytic distinction between simple redistribution and social insurance. In the real world economic risk exposure is often inversely related to income or wealth. Factors affecting demand for insurance and redistribution intertwine in complicated ways. Separating insurance effects (desire to insure against bad states) from redistributive concerns (desire to equalize relative outcomes across individuals or groups) is a key technical challenge. Most of the experimental literature examines voting in groups over explicitly redistributive policies (Agranov and Palfrey, 2014; Cabrales et al., 2012; Rutstrom and Williams, 2000). ${ }^{3}$ The few studies that examine social insurance (Barber et al., 2013; Esarey et al., 2011a) approach the insurance-versus-redistribution issue in different ways. In this study we use our experimental design to explicitly avoid any concern with redistribution, both within and across "households," thereby isolating the income dependency and the insurance concerns that motivate this paper.

\subsection{Household economics and gendered voting}

The voluminous literature on the economics of the household largely examines consumption, intra-household resource allocation, and labor supply decisions (Ashraf, 2009; Fortin and Lacroix, 1997; Gray, 1998; Hotz et al., 2013; Lundberg and Pollak, 1996). In this literature there is a division among those who view the household as a unitary actor and those taking a more complicated view of intrahousehold relations and decision-making. ${ }^{4}$ For political economists there is good reason to adopt the latter view. ${ }^{5}$ This literature, however, largely ignores political economy issues.

In political science there is a parallel literature on gender differences in voting, based on an observation that women in rich countries tend to identify more with and vote for left-leaning parties. Edlund and Pande (2002), for instance, find evidence that women have become more left-leaning in their voting behavior, which the authors correlate with lower marriage rates and higher divorce rates. However, in the American context, Burden (2008) finds that this partisan gender gap shrinks markedly when survey questions prime "feelings" rather than "thoughts." Additionally, Finseraas et al. (2012) use a Norwegian data set to evaluate the findings of Edlund and Pande (2002). They find that gender differences are largely due to more left-leaning voting by single women, with no robust effect of divorce risk or labor force participation.

Iversen and Rosenbluth (2010) provide the most articulated link between the household

\footnotetext{
${ }^{3}$ Subjects have generally shown a willingness to vote in favor of redistribution to some degree, though in-group favoritism is commonly found (Chen and Li, 2009; Klor and Shayo, 2010) and contextual factors can matter (Esarey et al., 2011b). Additionally, higher inequality is tolerated more when income differences are viewed as resulting from difference in effort rather than simply good or bad luck (Almås et al., 2010; Bogach et al., 2013; Esarey et al., 2011a).

${ }^{4}$ See Bateman and Munro (2013) for a detailed review.

${ }^{5}$ Lundberg et al. (1997) exploit an exogenous policy change in the UK to provide evidence against the unitary household model.
} 
economics and gender voting gap literatures. In their telling household economic decisions are the result of bargaining between partners. Should the partnership dissolve each partner faces different outside options; the quality of each partner's outside option determines bargaining leverage inside the partnership. External macroeconomic structures, in turn, determine the relative value of men's versus women's labor in the labor market, which then determine the outside option for women. Where women have poor outside options, policies "that favor the male breadwinner are therefore also policies that benefit women who are more or less completely dependent on their husbands" (Iversen and Rosenbluth, 2010, 115). But there are two wrinkles here when it comes to social insurance. First, according to Iversen and Rosenbluth, women in the United States (where we gather our data) have relatively good outside options due to the "general skills" nature of the American political economy. Second, the expected gender-based differences in political preferences arise around issues of public employment and child care. "[M]any of the other spending questions-about pensions, unemployment, and so on-are not clearly related to gender conflict." (Iversen and Rosenbluth, 2010, 119) So while we may see gender differences in partisan support it is not clear they will be visible in levels of support for specific welfare policies.

In our experiments we bracket concerns with intrahousehold bargaining in order to focus directly on the relationship between dependency structure and political preferences. Partnerships are induced randomly and there is no ability to dissolve them. The within-partnership division of income is fixed exogenously as are the labor market opportunities available to subjects. We ask whether there is evidence of a "dependency effect" even in the absence of or in addition to more complicated intrahousehold relations.

\subsection{Dependency, risk, and implications for social insurance de- mand}

People bound together in dependency relationships might view income insurance differently than those who are not, but the directionality of this relationship is not obvious. A variety of other-regarding payoff functions have been developed and evaluated in the theoretical and empirical economics literatures (Bolton and Ockenfels, 2000; Charness and Rabin, 2002; Falk and Fischbacher, 2006; Fehr and Schmidt, 1999; Rabin, 1993). While these models generate richer predictions about cooperative behavior and envy, none readily admits a role for a dependency effect, especially an asymmetric one.

Psychologists and marketing researchers have explored household dependency relations. Recent work from consumer research theorizes that dependency relationships may in fact change individuals' preferences, a stark departure from the intrahousehold bargaining research which assumes family members with fixed, stable preferences. Simpson et al. (2012) develop an informal model of dyadic decision making in which each member of a household has preferences and attitudes that affect the attitudes and preferences of their partner (see also Bagozzi (2012) and Gorlin and Dhar (2012)). Research in regulatory focus theory (Higgins, 1998; Lee et al., 2000; Zhou and Pham, 2004) finds that an interdependent outlook shifts an individual's focus from promotion goals to prevention goals. Also in this field, 
Hamilton and Biehal (2005) find that making dependency salient leads to loss-minimizing decisions consistent with increased risk aversion. However, there is evidence that this increased loss sensitivity may be more nuanced: Mandel (2003) finds that someone with an interdependent focus may engage in more financially risk-seeking behavior if "social risk" the risk of causing disappointment or disapproval - is salient.

In a closely related area, scholars examine how risk preferences differ between individuals and households, finding that decisions made jointly are generally more risk averse than those made by individuals (Abdellaoui et al., 2013; Bateman and Munro, 2005; Bone et al., 1999; Braaten and Martinsson, 2015; Carlsson et al., 2013; de Palma et al., 2011; Munro et al., 2013). Several of these studies involve real-life couples engaged in abstract joint decisions over risky lotteries. Clarke and Kalani (2011) design a framed field experiment to study demographic effects on take-up of microinsurance (such as rainfall and other index insurance) among residents in rural Ethiopia. Though household structure is not focal in their analyses, they find a significant link between measured household risk aversion and enrollment in microinsurance. However, the voting decisions that interest us are not in fact joint decisions, even if they are correlated within households. Findings on risk tolerance within couples may translate to voting for social insurance programs, but the direct connection has not yet been made.

For their part, marketers of private insurance and other financial products often emphasize dependency relationships in their advertisements, as depicted in Figure $1{ }^{6}$ Hopper (1995) points out that families, not individuals, are the predominant purchasers of financial services and investment products. Marketing messages should therefore target both members of a household as well as the connection between members. Further research into the determinants of life insurance purchases suggests family dynamics play a key role (Anderson and Nevin, 1975; Ferber and Lee, 1980; Goldsmith, 1983; Zietz, 2003).

Clearly dependency relationships are important for joint decisions, especially insurance purchasing. There is some evidence that dependency status may, in fact, affect individual preferences. But all of this research emphasizes mutual or symmetric dependency, in contrast to the political economy of the household literature with its emphasis on differential outside options and asymmetric dependency. Much of the literature looks at joint economic decisions with very little discussion of political preferences. And voting decisions are, ultimately, individual-level choices, not joint ones. Existing bodies of theory provide minimal guidance on what to expect. We therefore view dependency effects on political preferences, especially for welfare state policies, as an overlooked area of research. The existence, directionality, and symmetry of such effects are empirical questions.

\footnotetext{
${ }^{6}$ Hamilton and Biehal (2005) refer to a Scudders Investments advertisement that asks "What if your kid gets into Harvard? What if your mother needs long-term care? What if both happen at the same time?" This focus on responsibility to others, they argue, primes an interdependent outlook, increasing concern for minimizing losses.
} 

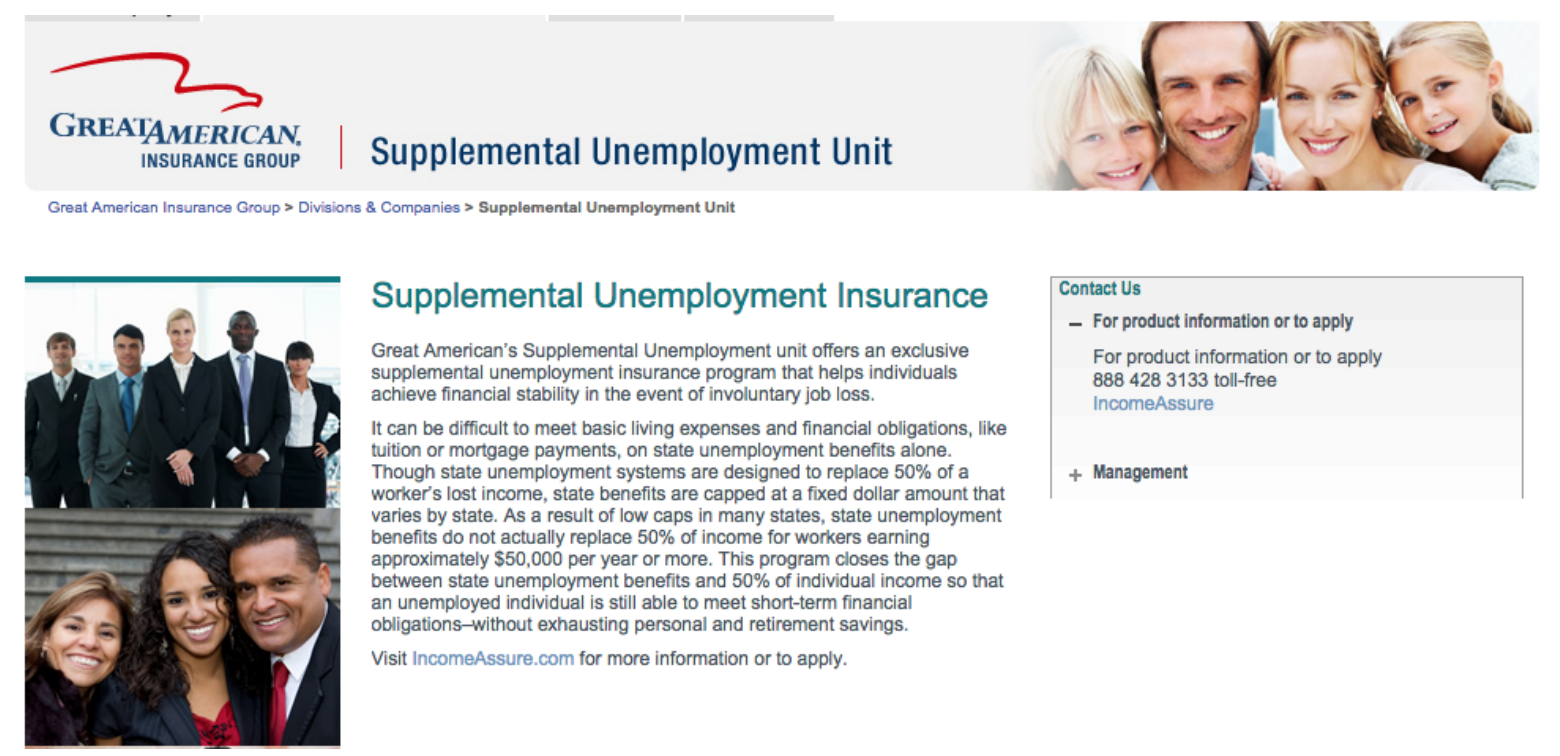

Supplemental Unemployment Insurance

Great American's Supplemental Unemployment unit offers an exclusive supplemental unemployment insurance program that helps individuals achieve financial stability in the event of involuntary job loss.

It can be difficult to meet basic living expenses and financial obligations, like tuition or mortgage payments, on state unemployment benefits alone. Though state unemployment systems are designed to replace $50 \%$ of a worker's lost income, state benefits are capped at a fixed dollar amount that varies by state. As a result of low caps in many states, state unemploymest benefits do not actually replace $50 \%$ of income for workers earning approximately $\$ 50,000$ per year or more. This program closes the gap between state unemployment benefits and $50 \%$ of individual income an unemployed individual is still able to meet short-term financial
obligations-without exhausting personal and retirement savings.

Visit IncomeAssure.com for more information or to apply.

\section{BB\&T Insurance Services \\ Global Resources - Client Focused}

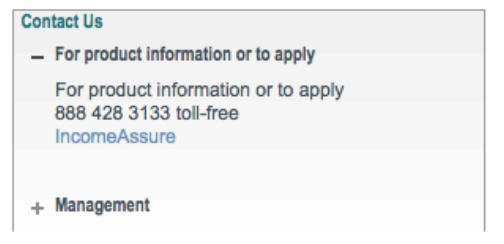

Find an Agent Who We Are

\begin{tabular}{llll} 
& & Business Personal \\
\hline Home Property Vehicle Life Insurance Health \& Accident Risk Management
\end{tabular}

\section{Supplemental Unemployment Insurance}

\section{Could your family live on $\$ 22,000$ \\ a year?}

The average unemployed person has been out of work for 40 weeks. Since state unemployment typically pays only $\$ 60$ a day, that's like living on a salary of less than $\$ 22,000$ a year.

State unemployment benefits were designed to replace $50 \%$ of a worker's lost income; however, all states now cap the benefit amounts. If you earn more than $\$ 50,000$ a year, unemployment benefits won't come close to $50 \%$ of your former salary.

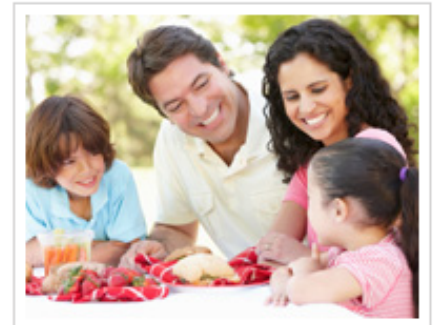

Get a Quote

Figure 1: Two examples of the marketing of private sector unemployment insurance in the United States. Accessed April 1, 2015.

\subsection{Expectations}

Existing work across several disciplines suggests that dependency should "matter." Isolating these relationships in an observational setting would be impossible, so we turn to the lab. In 
the experiment detailed in the next section we manipulate the two key variables that emerge from the discussion above: labor market risk and dependency status. A key innovation of this study is an explicit consideration of asymmetric dependency.

We treat single subjects with no household ties as the "control" condition, representing the setup assumed in most extant models of social insurance. We examine whether subjects are sensitive to increased labor market risk, expecting subjects in high risk treatments to vote for insurance at higher rates than those at lower risk (holding fixed insurance contributions). Second, we examine whether dependency matters. To achieve this, we construct three conditions. The first has subjects on their own, the "control" condition just mentioned. The second and third embed subjects in randomly constructed pairs. In one of these paired treatments both subjects are able to earn income and experience unemployment; we refer to this as the "paired, dual-earner" treatment. In the second paired treatment only one member of the pair (randomly determined) can earn (or suffer unemployment) while the other simply votes and shares in the earner's income. We call this the "paired, single-earner" condition. If dependency matters then, conditioning on risk, we should see a difference in voting for social insurance between those paired off and those on their own. We compare the subjects in the paired, single-earner treatment to those on their own to explore whether there is any asymmetry in the dependency effect, i.e., whether subjects factor in their partner's vulnerability (if the "breadwinner" is more supportive of insurance) or they are more sensitive to risk when they, themselves, are unable to work for a wage (if the "homemaker" is more supportive of insurance).

Our key outcome of interest is the subjects' voting behavior over social insurance policies. In the Appendix $\mathrm{C}$ (online) we briefly discuss subjects' effort levels in the experiment as a function of risk and dependency. We do this to show the extent of subject learning within experimental sessions and document that labor supply (as measured by task effort) does not differ significantly by experimental treatment.

\section{The Lab Experiment}

\subsection{Experimental design}

We conducted experimental sessions at the University of Wisconsin BRITE lab and the xs/fs lab at Florida State University. Wisconsin subjects were recruited from large introductory courses and were told they would be participating in a political behavior research study that would last under two hours and pay roughly $\$ 20-30$, including a fixed show-up fee. Recruiting at Florida State was done through ORSEE (Greiner, 2004). All sessions in both locations were conducted using computer terminals separated by privacy dividers. The experimental software was implemented in zTree (Fischbacher, 2007). Once all subjects had signed a consent form, instructions were distributed and read aloud, allowing for any questions to be answered publicly.

Subjects in each Wisconsin session were divided into groups of 8-12, with one or two 
groups in each session. ${ }^{7}$ Sessions at Florida State divided 24 subjects into three groups of eight. Randomization and treatment assignment occurred at the session level.

Each session had two stages. The first stage consisted of 10 production rounds in which the subjects earned money by completing an identical task. The second stage consisted of six guaranteed rounds after which we implemented a random stopping rule so that subjects had a $75 \%$ chance of seeing an additional round. In expectation subjects played a total of 20 rounds. The maximum number of rounds is 29 and minimum is 17 with an average of 22 .

In each production round subjects worked at a real-effort "slider" task (Gill and Prowse, 2011, 2012). In this task, subjects see 48 "slider bars" scattered on the screen (see figures in online Appendix A) with a peg positioned at the left-most edge of each slider. Subjects used their mouse to drag the peg to the exact center of each slider, successfully completing the item when the number to the right of the slider read "50." All subjects were given a two-minute practice round to familiarize themselves with the slider task before round one. Subjects were paid a 120 ECU (experimental currency unit) fixed "wage" per round in addition to a 10 ECU "commission" per completed slider, with earnings accumulating over all rounds of the experiment. ${ }^{8}$ The fixed wage and commission rates were chosen so that the fixed wage will equal approximately one third of the expected per-round compensation, based on past experience with the sliders task. ${ }^{9}$ In other words, we expect the piece rate earning to be about double the base wage.

We have two experimental manipulations: unemployment risk (high or low) and dependency status (single; paired, single-earner; and paired, dual-earner). The dependency manipulation is meant to simulate, abstractly, various ways in which households might interact with the labor market. In the "single-earner-only" treatment subjects were not paired with anyone else and their payoffs depended only on their own actions and the random parameters of the experiment. In the "paired, dual-earner" treatment subjects were randomly assigned a partner. Both members of the pair were able to work at the slider task during production rounds as just described. Each member of the pair is independently subject to the same unemployment risk. In the "paired, single-earner" treatment subjects were randomly assigned a partner. At the beginning of the first stage partners were randomly assigned a role-active or passive-such that each pair had one of each type. The active participant (corresponding to the notion of breadwinner) was able to work at the task, as described above, while the passive participant (i.e., the homemaker) was unable to work at the task during that stage. At the beginning of stage II the participants switched roles. ${ }^{10}$ In both the paired treatments subjects' earnings were split equally between the matched subjects. ${ }^{11}$ Subject pairs remain

\footnotetext{
${ }^{7}$ For example, if sixteen subjects showed up we could run a session with two groups of eight. Note that both groups receive the same risk and dependency treatment.

${ }^{8}$ Note that to avoid priming subjects we did not use the terminology of "wage", "commission", and "unemployment" in the experimental treatments. We use these terms here for ease of exposition.

${ }^{9}$ Gill and Prowse (2011) report that on average subjects completed 26 sliders in two minutes. In our sessions to date subjects are completing about 15 on average

${ }^{10}$ Subjects were told that their roles would be assigned at the beginning of each stage. They were not told, ex ante, that their roles would switch deterministically.

${ }^{11}$ Individual-level earnings were converted to dollars at a rate of 165ECU:\$1 for the Wisconsin sessions and 200ECU:\$1 for the FSU sessions. The two sites' conversion rates differ because the labs imposed different
} 
constant for all rounds in each stage.

We note immediately that our pairing protocol is quite weak. Pairing is anonymous, subjects are unable to communicate with one another, and there was no other intervention designed to increase the partner "bond." We view our experiment as a difficult test for any dependency effect, as non-findings may be attributable to an insufficient bond between subjects. We also note that our paired, single-earner condition is not an instance of one partner simply having a weak "outside option" since partnerships cannot dissolve and the income sharing rule is fixed in our experiment.

We explore two different risk levels to see whether subjects are reacting to risk as we would expect and to ensure that we have some subjects who experience several rounds of "unemployment." In each production round there was a probability, $p$, that a subject would become "unemployed", i.e., be forced to sit out for a production round and forgo earnings. The value of $p$ is constant for an entire experimental session and common for subjects within a session. For the low risk treatments $p=0.05$, approximately the American unemployment rate under tight labor market conditions. For the high-risk treatments we set $p=0.25$, approximately equal to what we are currently witnessing in the depressed parts of Europe. All subjects were told the value of $p$ for their session. We also explained that unemployment risk is independent across subjects and that each subjects' unemployment risk is independent of their task performance and that of any other subject. As part of the comprehension quiz subjects were asked to state the unemployment risk for their session; the session was not allowed to proceed until all subjects answered this question correctly.

Before each stage subjects were presented with the opportunity to vote over a social insurance policy designed to partially insure participants against income losses from "unemployment." Unlike other experimental studies focusing on the redistributive aspects of social insurance (Barber et al., 2013; Esarey et al., 2011a), we take the policy proposal as exogenous. ${ }^{12}$ Specifically, participants voted for either "option A" in which no insurance was provided and no taxes were levied or "option B" in which unemployed participants are guaranteed 120ECU for that round while all working participants contribute $7 \mathrm{ECU}$ to an insurance fund. To explicitly avoid any redistributive consequences we do not require the budget to balance, i.e. expenditures for insurance payments could exceed subjects' contributions or there could be a surplus. Any deficit or surplus disappears at the end of the experiment; subjects are informed of all this.

The group decision is taken by majority vote. All subjects are able to vote, including the passive subjects in the paired, single-earner treatment. Voting is compulsory and ties are broken by random draw. Subjects were shown the adopted policy and the number of votes for and against.

Note that the 7ECU insurance contribution, constant across both risk treatments, was derived as the value that would lead the insurance budget to balance in expectation under

fixed show-up fees ( $\$ 5$ at Wisconsin and $\$ 10$ at FSU). The conversion rates were intended to make earnings approximately equal across sites.

${ }^{12}$ These other studies had subjects enter a tax rate and took the median entry as the group's choice, recalling Meltzer and Richard (1981). 
the low risk condition, assuming an average slider score of $26 .{ }^{13}$ This contribution is far less than the amount required to balance the budget under the high risk condition. If subjects understand the situation then they should certainly vote in favor of insurance in the high risk setting since their premiums are, in effect, massively subsidized. The decision is more ambiguous in the low risk treatment.

The first vote takes place before subjects learn their employment status and, in the paired-single earner treatment, their role. The second vote takes place after the completion of round ten. Among the subjects in the paired, single earner treatment, none had prior experience for the first vote but for the second vote, half had been active during stage I and the other half passive. Importantly, neither group knew what its status would be for stage II at the time of the vote. Subjects in this treatment condition cast their second vote before they were told their role (active or passive) for the stage II rounds.

We emphasize that our protocol explicitly excludes redistributive concerns (whether from richer to poorer or more productive to less so) embedded in many real-world social insurance programs as well as the experimental (Barber et al., 2013; Esarey et al., 2011a) and observational (Iversen and Soskice, 2001; Nickelsburg and Timmons, 2012; Rehm, 2009, 2011; Scheve and Stasavage, 2006) studies that look at them. Other studies ask respondents to enter a preferred tax rate and then pay subjects as a proportion of group income, implying distributive consequences to insurance. In our set up, we have subjects vote before they fully realize their level of productivity. We also set contribution rates exogenously. But most importantly, we do not force the budget to balance breaking any direct dependence between payments to subjects. It is now possible for everyone to be a net beneficiary or a net contributor; a payment to one does not come out of the pocket of another.

At the beginning of each production round all subjects were informed whether they would participate in the task that round or sit out. Participating subjects then had two minutes to work at the sliders task while those sitting out saw a blank screen. At the end of each production round subjects in the single earner treatment saw whether they participated in the task, their performance in completed sliders, and their payoff in ECU. They also saw this information for prior rounds. Subjects in the Paired treatments saw this information for themselves as well as their partner. Figure 3 in Appendix A (online) displays a screen shot of the feedback given to participants.

After the final round, all participants completed a questionnaire. All subjects were paid privately, in cash, at the conclusion of the session.

We conducted fifteen experimental sessions composed of 35 unique groups for a total of 282 valid participants. Details on the number of subjects in each treatment from each location are presented Appendix B (online).

\subsection{Experimental results}

Figure 2 displays the basic results for the voting experiment. Each panel represents one of the different dependency treatments while the colors of the bars depict risk levels and roles

\footnotetext{
${ }^{13}$ In fact it is slightly more than the (expected) budget-balancing contribution of 6.31
} 
(for the paired, single earner treatment). The points represent the proportion of subjects casting votes in favor of the insurance scheme, with associated $95 \%$ confidence intervals. Tables reporting numerical versions of these results along with sample sizes are presented in Appendix B (online). There are three things to note: the high levels of support for insurance; the responsiveness to risk; and the asymmetric dependency effect.

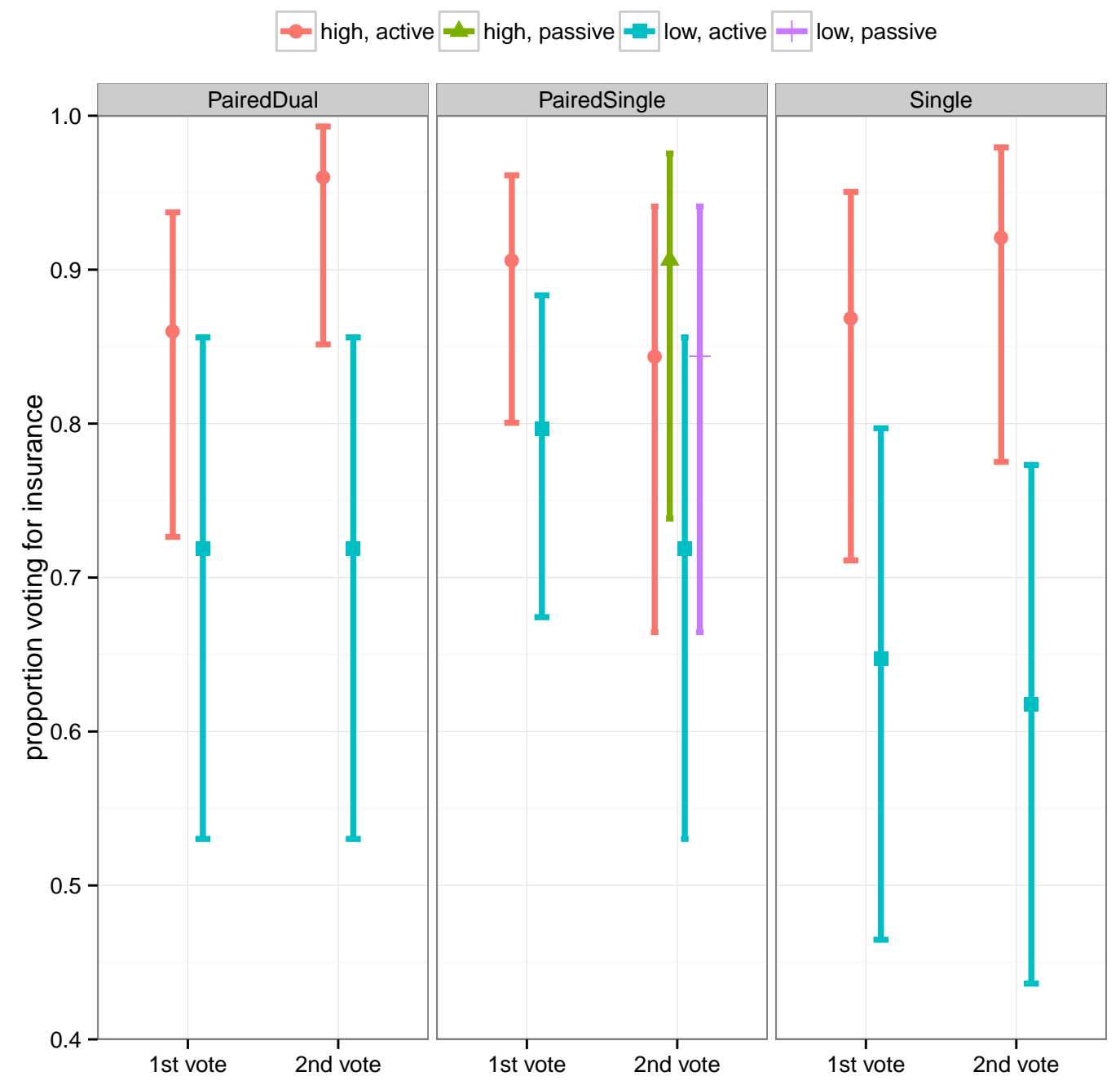

Figure 2: Ex ante and mid-session voting for social insurance by dependency treatment, unemployment risk level (low risk $=5 \%$; high risk $=25 \%$ ), and stage I role. Note that subjects in the paired, single treatment did not know their role for stage I at the time of casting the first vote nor did they know their roles for stage II at the time of casting the second vote.

First, regardless of risk or dependency considerations, subjects voted for insurance by 
large margins. ${ }^{14}$ There were only two groups-both in the same low-risk dual-earner sessionin which a majority of the subjects voted against insurance. While unsurprising in the highrisk treatments, the strong support for insurance under low risk is noteworthy: under low risk the price for insurance slightly exceeds both the amount needed to balance the budget and the expected individual benefit for any player. ${ }^{15}$ The initial support for insurance in the ex ante vote might be attributed to subjects' lack of familiarity with the slider task. Support for insurance did weaken in the second vote in the low-risk treatments, at least in the paired-single, active earners and single earner dependency conditions. But this weakening of support was modest and not enough to switch the group decisions in any case. Subjects appear notably risk averse in this experiment.

Second, as expected, we recovered a strong sensitivity to risk. Across all three dependency conditions, subjects in the high risk treatments were significantly more likely than those in the low-risk analogue to vote for insurance at the first opportunity. In the single-earner and paired, dual-earner treatments these gaps grew between the first and second votes. Averaging across all dependency conditions the difference in pro-insurance voting proportions between high and low risk was fourteen percentage points in the first vote $\left(\chi^{2}=9.5, p=0.002\right)$. This gap grew to nineteen percentage points by the second vote $\left(\chi^{2}=17.9, p \approx 0\right)$, a large number all the more remarkable given the high overall levels of support for insurance described above. Furthermore, changes in support for insurance from the first to the second vote responded differently in the two risk treatments. Among the the single and paired, dual-earner subjects, support increased in the high-risk condition but stayed about flat in the low risk conditions although none of these differences achieve statistical significance at $p \leq 0.05$.

Third, we find weak evidence for the hypothesis that simple dependency status per se affects willingness to support insurance policies. In the high risk setting we see voting for insurance at similarly high rates across all dependency treatments; these rates are sufficiently close that we cannot distinguish among any of them statistically. In the low-risk condition respondents in the paired treatments were marginally more supportive of insurance than subjects without dependents, but this difference was not significant. ${ }^{16}$ But in the low risk setting we see clear evidence that subjects who had been the passive member of a singleearner partnership during stage I were substantially more likely to cast votes for insurance at the second opportunity. The passive member of single-earner partnerships voted at the highest rates, 12 percentage points higher than subjects in the other paired treatments and 22 percentage points higher $\left(\chi^{2}=4.3, p=0.04\right)$ than subjects with no experimentally-induced dependency relationships. Subjects who were in the passive position in a partnership were, by the second vote, more likely to vote in favor of insurance than those in the any of the

\footnotetext{
${ }^{14}$ In future work we plan to make insurance more expensive to induce greater heterogeneity in voting behavior.

${ }^{15}$ In the low-risk treatment the subject pays in 70ECU over ten rounds and expects to receive $60 \mathrm{ECU}$.

${ }^{16}$ Looking only at the second vote and the low-risk condition we see that the proportion of subjects in paired treatments (averaged over single- and dual-earner) voting for insurance was 14 percentage points higher rate than those on their own. This difference, while large, is not statistically significant at conventional thresholds.
} 
other dependency conditions, at least in the low risk treatment.

Regression analysis lets us examine these results more precisely. Table 1 displays logistic regression estimates for subjects' first votes for insurance. We fit two models here. Model 1 includes only indicators for the the randomly assigned dependency and risk treatments; the individual earner, low risk treatment is the reference category. The second model also conditions on subjects' gender, age, lab site, whether the subject is employed in the "real world," and whether the subject is cohabiting with a spouse or domestic partner in addition to the experimental treatments. Including these additional covariates causes us to lose 17 observations due to nonresponse on the questionnaire.

The regression results mirror those depicted for the first vote in figure 2: subjects are responsive to risk but little else seems to matter. Demographic covariates have no predictive power in the first vote.

Table 2 displays estimates from four logistic regression models on the second vote for social insurance. Model 3 includes only experimental variables while model 5 includes the additional covariates of gender, age, lab site, employment and domestic status as well as the subjects' experiences during the first stage: the number of rounds in which the subject was forced to sit out and the number of rounds the subject's partner sat out. Models 4 and 6 also condition on subjects' initial vote. ${ }^{17}$

By the second vote several patterns emerge. Unsurprisingly, we continue to see the strong and robust risk effect across all model specifications. The rate of pro-insurance voting in the high risk setting is so elevated that subject behavior across dependency treatments is indistinguishable.

More interesting is our ability to discern a significant asymmetric dependency effect under lower risk at the second vote, taken after subjects have some experience with the task and their roles. ${ }^{18}$ Subjects in the passive role of the paired, single-earner treatment, i.e., those who have just had the experience of being dependent on someone else, are significantly more likely to support insurance than otherwise similar subjects able to earn on their own. This finding is robust to the inclusion of a variety of covariates, including the first vote. Again we find no added value from including covariates. This is particularly important since we are conditioning on both own and partner's experience with unemployment (number of rounds sitting out). The actual experience of unemployment has no discernible effect on the likelihood of pro-insurance voting once we know the risk of unemployment and dependency relationships. This gives us more confidence that our findings can be interpreted as a dependency effect rather than simply the result of having sat out ten consecutive rounds.

The model has a series of interesting comparisons that are difficult to extract from the table. To better interpret findings we use Model 3 to generate the "relative risks" of vot-

\footnotetext{
${ }^{17}$ Note that both the subjects' experience with "unemployment" and the first vote can be viewed as "post treatment" variables that should not be conditioned upon. We include them here since (i) there is some heterogeneity in unemployment experience even within risk treatments; (ii) the risk treatment could be viewed as composed of two parts: informing the subject of risk and the actual realization of that risk; (iii) the first vote occurred prior to the administration of the active/passive role treatment in the paired, single condition.

${ }^{18}$ See Appendix C (online) for a discussion of task effort and learning.
} 
Table 1: Logistic regression parameter estimates for first vote on social insurance. The single-earner, low risk treatment is the reference category.

\begin{tabular}{|c|c|c|}
\hline & \multicolumn{2}{|c|}{ Affirmative first vote } \\
\hline & Model 1 & Model 2 \\
\hline Constant & $\begin{array}{c}0.606^{*} \\
(0.359)\end{array}$ & $\begin{array}{c}1.310 \\
(1.765)\end{array}$ \\
\hline High, Paired Dual & $\begin{array}{l}1.209^{* *} \\
(0.543)\end{array}$ & $\begin{array}{l}1.256^{* *} \\
(0.560)\end{array}$ \\
\hline High, Paired Single & $\begin{array}{c}1.663^{* * *} \\
(0.559)\end{array}$ & $\begin{array}{c}1.649^{* * *} \\
(0.583)\end{array}$ \\
\hline High, Single & $\begin{array}{l}1.281^{* *} \\
(0.599)\end{array}$ & $\begin{array}{l}1.409^{* *} \\
(0.622)\end{array}$ \\
\hline Low, Paired Dual & $\begin{array}{c}0.332 \\
(0.532)\end{array}$ & $\begin{array}{c}0.393 \\
(0.543)\end{array}$ \\
\hline Low, Paired Single & $\begin{array}{c}0.761 \\
(0.475) \\
\end{array}$ & $\begin{array}{c}0.903 \\
(0.560)\end{array}$ \\
\hline Wisconsin & & $\begin{array}{l}-0.048 \\
(0.407)\end{array}$ \\
\hline Male & & $\begin{array}{l}-0.507 \\
(0.357)\end{array}$ \\
\hline Cohabiting & & $\begin{array}{l}-0.275 \\
(0.740)\end{array}$ \\
\hline Employed & & $\begin{array}{l}-0.577 \\
(0.383)\end{array}$ \\
\hline Birth year & & $\begin{array}{l}-0.001 \\
(0.076)\end{array}$ \\
\hline$N=$ & 282 & 265 \\
\hline Log Likelihood & -128 & -115 \\
\hline $\mathrm{AIC}$ & 269 & 252 \\
\hline
\end{tabular}


Table 2: Logistic regression parameter estimates for the second vote on social insurance. The single-earner, low risk treatment is the reference category.

\begin{tabular}{|c|c|c|c|c|}
\hline & \multicolumn{4}{|c|}{ Affirmative second vote } \\
\hline & Model 3 & Model 4 & Model 5 & Model 6 \\
\hline Constant & $\begin{array}{c}0.480 \\
(0.353)\end{array}$ & $\begin{array}{c}-0.884^{*} \\
(0.465)\end{array}$ & $\begin{array}{c}2.671 \\
(2.284)\end{array}$ & $\begin{array}{c}2.362 \\
(2.718)\end{array}$ \\
\hline 1 st vote & & $\begin{array}{c}2.240^{* * *} \\
(0.384)\end{array}$ & & $\begin{array}{c}2.599^{* * *} \\
(0.458)\end{array}$ \\
\hline High, Paired Dual & $\begin{array}{c}2.698^{* * *} \\
(0.803)\end{array}$ & $\begin{array}{c}2.528^{* * *} \\
(0.850)\end{array}$ & $\begin{array}{c}2.781^{* * *} \\
(0.835)\end{array}$ & $\begin{array}{c}2.830^{* * *} \\
(0.910)\end{array}$ \\
\hline High, Paired Single (passive) & $\begin{array}{l}1.789^{* *} \\
(0.702)\end{array}$ & $\begin{array}{c}1.339^{*} \\
(0.760)\end{array}$ & $\begin{array}{c}2.232^{* * *} \\
(0.758)\end{array}$ & $\begin{array}{l}2.035^{* *} \\
(0.849)\end{array}$ \\
\hline High, Paired Single (active) & $\begin{array}{l}1.207^{* *} \\
(0.601)\end{array}$ & $\begin{array}{c}0.680 \\
(0.664)\end{array}$ & $\begin{array}{l}1.624^{* *} \\
(0.653)\end{array}$ & $\begin{array}{c}1.233^{*} \\
(0.731)\end{array}$ \\
\hline High, Single & $\begin{array}{c}1.977^{* * *} \\
(0.697)\end{array}$ & $\begin{array}{l}1.707^{* *} \\
(0.755)\end{array}$ & $\begin{array}{c}2.184^{* * *} \\
(0.725)\end{array}$ & $\begin{array}{l}1.742^{* *} \\
(0.784)\end{array}$ \\
\hline Low, Paired Dual & $\begin{array}{c}0.459 \\
(0.528)\end{array}$ & $\begin{array}{c}0.391 \\
(0.603)\end{array}$ & $\begin{array}{c}0.607 \\
(0.555)\end{array}$ & $\begin{array}{c}0.579 \\
(0.640)\end{array}$ \\
\hline Low, Paired Single (passive) & $\begin{array}{l}1.207^{* *} \\
(0.601)\end{array}$ & $\begin{array}{c}1.022 \\
(0.671)\end{array}$ & $\begin{array}{l}1.914^{* *} \\
(0.749)\end{array}$ & $\begin{array}{l}1.960^{* *} \\
(0.843)\end{array}$ \\
\hline Low, Paired Single (active) & $\begin{array}{c}0.459 \\
(0.528)\end{array}$ & $\begin{array}{c}0.202 \\
(0.600)\end{array}$ & $\begin{array}{l}1.205^{*} \\
(0.671)\end{array}$ & $\begin{array}{c}1.048 \\
(0.775)\end{array}$ \\
\hline Wisconsin & & & $\begin{array}{c}0.565 \\
(0.496)\end{array}$ & $\begin{array}{c}0.715 \\
(0.558)\end{array}$ \\
\hline Male & & & $\begin{array}{l}-0.434 \\
(0.382)\end{array}$ & $\begin{array}{l}-0.145 \\
(0.425)\end{array}$ \\
\hline Cohabiting & & & $\begin{array}{l}-1.007 \\
(0.772)\end{array}$ & $\begin{array}{l}-1.224 \\
(0.898)\end{array}$ \\
\hline Employed & & & $\begin{array}{c}0.230 \\
(0.390)\end{array}$ & $\begin{array}{c}0.632 \\
(0.451)\end{array}$ \\
\hline Birth year & & & $\begin{array}{l}-0.108 \\
(0.098)\end{array}$ & $\begin{array}{l}-0.191 \\
(0.120)\end{array}$ \\
\hline Rounds sat out & & & $\begin{array}{l}-0.016 \\
(0.130)\end{array}$ & $\begin{array}{c}0.051 \\
(0.149)\end{array}$ \\
\hline Rounds partner sat out & & & $\begin{array}{c}0.043 \\
(0.167) \\
\end{array}$ & $\begin{array}{c}0.017 \\
(0.187)\end{array}$ \\
\hline $\bar{N}=$ & 282 & 282 & 265 & 265 \\
\hline Log Likelihood & -117 & -100 & -102 & -84 \\
\hline $\mathrm{AIC}$ & 251 & 217 & 235 & 200 \\
\hline
\end{tabular}




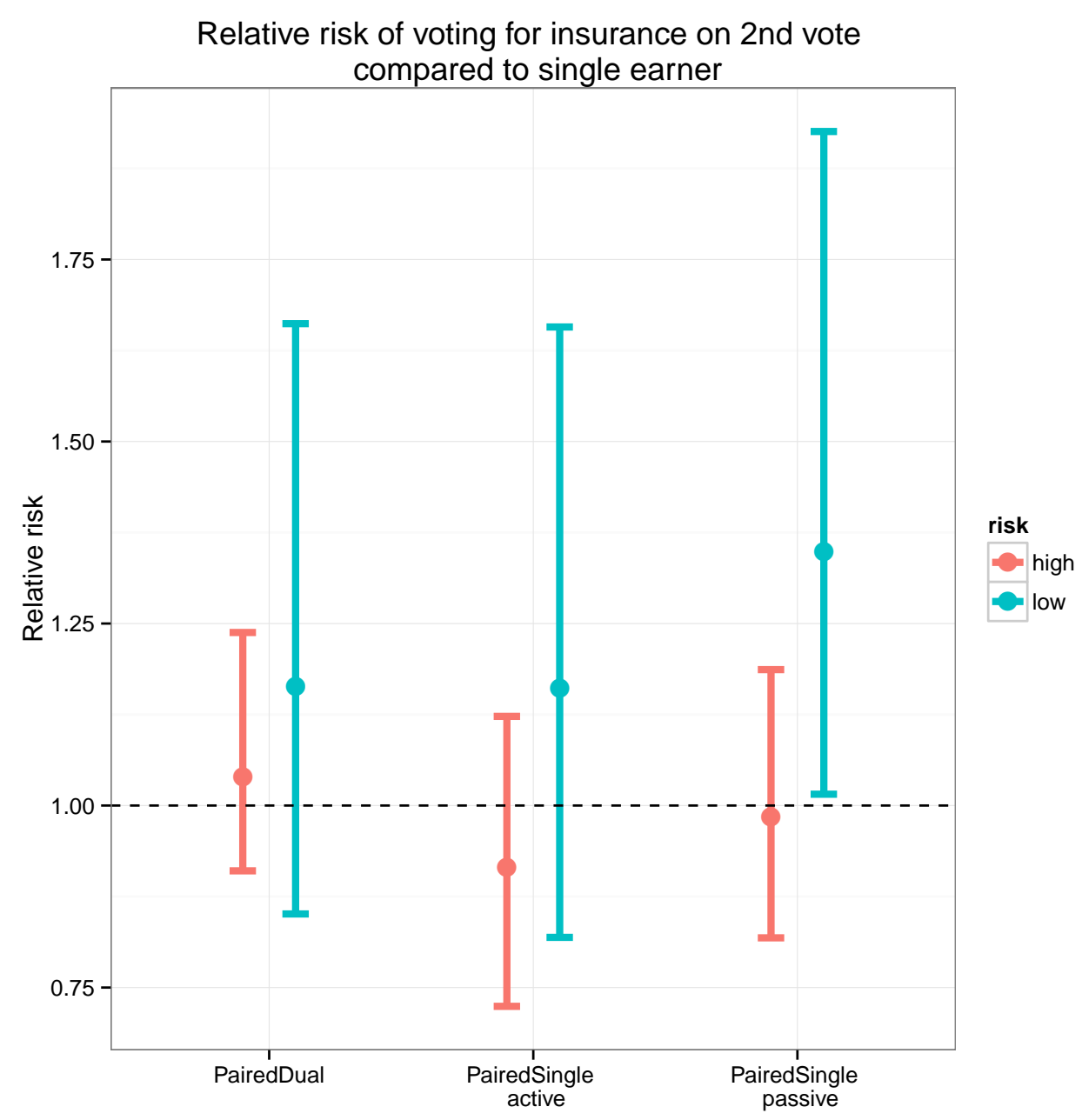

Figure 3: Relative risk of voting for social insurance at the second vote comparing subjects to those in the single-earner condition at the same unemployment risk level. Points are median estimates from 1,000 simulations and vertical bars are 95\% confidence intervals. Estimates derived from Model 3.

ing for insurance at the second vote. Specifically, we divide the predicted probability of a pro-insurance vote for subjects in a particular treatment by the predicted probability of a pro-insurance vote for a single-earner of the same unemployment risk level. ${ }^{19}$ A value of unity indicates that the subjects in the two conditions are equally likely to vote for insurance. Relative risks greater than one indicate percent by which a subject's probability of supporting insurance exceeds that for a single earner facing the same unemployment rate.

\footnotetext{
${ }^{19}$ For example, to evaluate the increased likelihood that a passive member of a single-earner partnership in the low risk condition would vote for insurance we divide that subject's predicted probability of voting for insurance by the predicted probability for a subject in the low risk, single earner treatment.
} 
The figure shows that passive subjects in the single-earner, low unemployment condition are, on average, $35 \%$ more likely to vote for insurance than a similar single earner. We are unable to distinguish any of the other dependency/risk combinations from their individual earner counterparts.

One may question whether a single-earner subject is the appropriate baseline for comparison. For example, why is the asymmetric dependency effect discernible only when we compare the passive member of a single-earner partnership to a solitary subject but not when we compare her to the active member of a single-earner partnership? We believe that the single-earner provides the appropriate baseline for two reasons. First, the existing theoretical and empirical literature motivating this study takes the hypothetical single individual as the prototype. Second, we have no ex ante reason to believe that the appropriate way to measure treatment effects is within a particular dependency treatment. Rather, we view the single earner as the benchmark against which to measure possible deviations among both the active and passive halves of single-earner partnerships. From a practical standpoint, the lack of a significant difference between the passive and active members of a single-earner partnership (or between active partners and single-earners) could arise for a variety of reasons, including weaker effects requiring bigger samples, an insufficiently strong partner bond in our experimental setting, or simply sampling variability. Appropriately evaluating these possibilities is an opening for additional research.

The laboratory experiment, even with its stylized setting and with no attempt at inducing any connection between subjects beyond anonymously sharing earnings, managed to uncover a significant asymmetric dependency effect. Prior to having any real experience with the task, subjects only displayed sensitivity to the stated risks of unemployment. After having some experience with the task and their roles, however, subjects who were randomly made dependent on the earnings and employment of a partner but who where unable to earn on their own were more supportive of insurance; subjects who were made jointly dependent but where both could earn showed no such difference in behavior.

\section{Evidence from Survey Data}

The lab findings allowed us to demonstrate a dependency effect even when partnering is exogenous, the redistributive effects of social insurance are removed, and real world household politics are assumed away. But we also use an undergraduate subject pool who are less exposed to adult household relationships and may be more selfish and narrowly "rational" (Belot et al., 2015). So how general are our findings? Are similar correlations visible in observational settings?

To answer to these questions we turn to the General Social Survey (GSS). In several years (1985, 1990, 1996, and 2000), the GSS asked respondents their attitudes about governmentprovided benefits for the unemployed. ${ }^{20}$ Critically, the GSS, alone among major social science

\footnotetext{
${ }^{20}$ The specific question came as part of a larger battery of questions on government spending. For our purposes, we are concerned with the following item: "Please indicate whether you would like to see more or less government spending in each area. Remember that if you say 'much more,' it might require a tax
} 
surveys, also includes questions asking about the respondents' own labor force participation as well as that of their spouse (if any). This allows us to classify respondents into six mutually exclusive categories, several of which correspond with our experimental conditions. ${ }^{21}$ The GSS unemployment benefits question has been analyzed in several other studies of social insurance (Howard, 2008; Lowery et al., 2013; Scheve and Stasavage, 2008).

For the purposes of this analysis, households containing partnered adults who are both in the labor force correspond with our "paired, dual-earner" experimental condition. Households comprised of two partnered adults where only one is in the labor force correspond with our "paired, single-earner" condition. These households are further disaggregated into the "passive" member who is not in the labor force and the "active" member who is in the labor force. ${ }^{22}$ Households headed by one unpartnered adult in the labor force correspond with our "single only" condition. For completeness, we also separate out partnered households where neither member is in the labor force (e.g., retired couples) and households headed by an unpartnered adult who is out of the labor force, but these categories do not correspond with any treatment conditions in the experiment. We also include the number of children under 18 living in the household.

The other key covariate related to our experiment is unemployment risk. We approach this in two ways. First, we include indicators for the respondents' and partners' current employment status. This corresponds to their actual unemployment experience rather than perceived risk. To capture risk we include (in Models 8-10) the unemployment rate for respondents' US Census Bureau geographic division in that survey year, ${ }^{23}$ as reported by the Bureau of Labor Statistics. Note that the maximum observed unemployment rate across GSS waves is $9 \%$, far below the maximum risk that we induced in the lab.

We condition on several covariates shown to influence individuals' support for social insurance spending in the existing literature: income, ${ }^{24}$ race (white or nonwhite), self-placement on a left-right ideological scale, ${ }^{25}$ partisan self-identification, ${ }^{26}$ religiosity, ${ }^{27}$ skill specificity, ${ }^{28}$

increase to pay for it: Unemployment benefits." Respondents could reply with one of five options from "Much Less" to "Much More" with a neutral midpoint.

${ }^{21}$ For a mapping of the GSS employment categories to our experimental conditions, see Appendix D (online).

${ }^{22}$ In these data partnered adults not in the wage labor force are almost always female. In the regression analyses that follow, we include controls for gender to allow for the possibility that attitudes about social insurance are attributable to differences by gender rather than dependency status.

${ }^{23}$ The nine category Census division is the lowest level of geography that is publicly available in the GSS.

${ }^{24}$ For income we assign each respondent the midpoint of the income bin she selected. We then reflate all income levels to 2006 dollars using the CPI. We omit any respondent not reporting income. Qualitative conclusions are unchanged if we impute missing values for income.

${ }^{25}$ Ideology was measured on a seven-point scale from "Very Liberal" $=-3$ to "Very Conservative" $=3$.

${ }^{26}$ On a seven-point scale from "Strong Democrat" $=-3$ to "Strong Republican" = 3. Respondents who reported belonging to some other party were grouped with the "Pure Independents."

${ }^{27}$ Following Scheve and Stasavage (2008) we use reported frequency of attendance at religious services.

${ }^{28}$ Skill specificity was calculated following the logic described in Iversen and Soskice (2001). The GSS includes Census occupation codes. We adapt the Iversen and Soskice (2001) method used on ISCO codes to the Census' classification scheme. Census occupational codes are arranged into several categories (e.g. Managers, Professionals, Farm, etc.). Iversen and Soskice (2001) measure skill specificity as the share of 
age, gender, and whether the respondent has a college degree. We also include year-specific dummies but omit them from the table for brevity.

Table 3 reports ordered logit regression results summarizing our findings from the GSS data. After conditioning on observable confounding factors, we find results that mirror those from the lab: relative to every other dependency group, those with a partner in the labor force but who were not themselves working were significantly more likely to favor increased spending on unemployment benefits. To allay concerns about the multicollinearity between gender and dependency status, Models 7 through 9 omit gender while Model 10 includes it. None of the other estimated coefficients in the model are affected by the presence of gender in the model. Compared to the the estimated effect of being the dependent partner in a two person household, other conditions are essentially indistinguishable from one another. We also find that those currently unemployed or with an unemployed partner are much more supportive of unemployment benefits, consistent with Margalit (2013). Note that the point estimate for own unemployment is estimated with considerably more precision and is about 20\% larger than that for partner's unemployment. Neither the number of children in the household nor the regional unemployment rate is a significant predictor of support for unemployment benefits. Interestingly, gender fails to show any predictive power once we account for dependency status.

all listed occupations in the classification scheme within a particular category divided by the share of the workforce that fall into that category. We use the distribution of occupations reported in the GSS as our measure of the labor force for each year of the survey. For example, in 2006 about $12 \%$ of the GSS respondents were classified into management occupations. These occupations account for a little over $5 \%$ of the total occupations listed in the census occupation codes. The estimated skill specificity for individuals working in management occupations in 2006 is simply $(0.05 / 0.12) * 100$. For models in the main text, we measure skill specificity as the greater of the reported values of the adults in the household. In Appendix F (online) we show that our results are robust using the minimum household score and the average household score. As a further complication, the 1985 wave used the 1970 Census occupational codes while the 1990, 1996, and 2006 data used the 1980 codes. Fortunately, the 1990 wave included both the 1970 and 1980 codes facilitating comparison between the two different classification schemes. For respondents in the 1990 wave, we calculated skill specificity based on both the 1970 and 1980 census codes. The estimated scores correlated at $r=0.5$. Excluding the 1985 wave from the analyses reported in this paper does nothing to change the substantive findings (if anything, they are strengthened). 


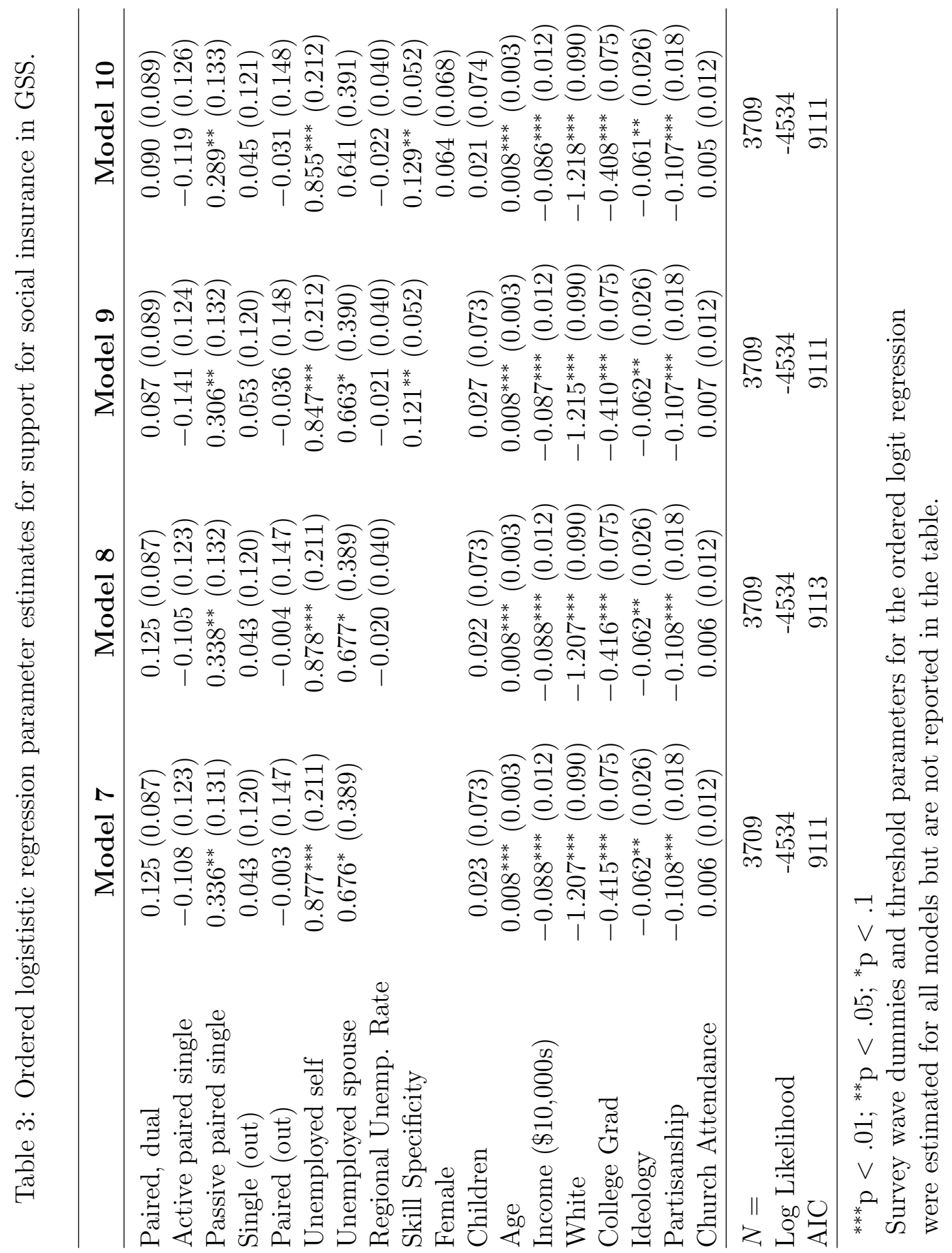


Findings for the other covariates are in line with the existing literature: whites, higher income individuals, those with more education, and more conservative respondents all are less supportive of unemployment spending. Contrary to Scheve and Stasavage (2008), religiosity is not an important predictor here. Skill specificity is a consistently positive and significant predictor of support for unemployment spending.

We check whether our dependency status results are in fact specific to unemployment by fitting similarly specified regressions for other questions that formed part of the government spending battery. ${ }^{29}$ Results do not show the same pattern as we observed for unemployment benefits. $^{30}$ Dependents were no more likely to prefer increased spending on any of the programs included in the GSS questionnaire than people who were otherwise similar in terms of the demographics and political attitudes. Effects of asymmetric dependency appear concentrated on respondent evaluation of labor market risk rather than producing a general dispositional shift in attitudes toward government actions.

We provide a more expansive substantive interpretation for the model in Figure $4 .{ }^{31}$ The solid line shows the distribution of the predicted effect of moving from "Single Only" (an unpartnered individual in the labor force) to "Passive Single" (the dependent member of a single earner household). After controlling for observable demographic and attitudinal factors, our hypothetical dependent is about 5 percentage points more likely to support either "more" or "much more" spending on unemployment benefits.

For comparison, the plot also shows the implied "effect" of moving two points in the Democratic direction on the partisan identification scale, from "Pure independent" to a weakly identifying Democrat (dashed line). The average predicted effect of asymmetric dependency is roughly equivalent to moving two points on the seven point party identification scale, although the implied effect of the latter is more precisely estimated.

Holding income constant while going from a single earner to the stay-at-home member of a two-adult household may not represent a realistic comparison. In Figure 5 we present a more realistic counterfactual. Given that total income covaries with the number of earners in a household, this figure shows the estimated difference in predicted probability of supporting more spending on unemployment benefits comparing an individual who is in a Paired Dual household with the average income of the other Paired Dual households in the sample (a little more than 0.5 a standard deviation above the mean level of income) to a dependent in a single earner home with the average income of the other single earner households in the sample (almost exactly the sample mean income). The estimated distribution of this effect is shown in the solid line of the figure.

\footnotetext{
${ }^{29}$ The other items included in the battery were spending on the environment, health programs, law enforcement, education, military, retirement, and the arts.

${ }^{30}$ For space considerations these results are relegated to Appendix E (online)

${ }^{31}$ The plot shows the results of 10,000 simulations from the sampling distribution holding all other variables in the model at their sample central tendencies. The hypothetical individual used as the example case is a 45 year old white female without a college degree. She does not have children living at home, is a political moderate, and does not identify with a political party. She attends church several times a year and is in a household that earns slightly more than $\$ 42,000$ (2006 dollars) per year. She lives in a region with $5.5 \%$ unemployment and has a skill specificity score of 1.1. The predicted probabilities were generated from the regression reported in Model 10.
} 


\section{Effect of Dependency Status on Support for Unemployment Spending}

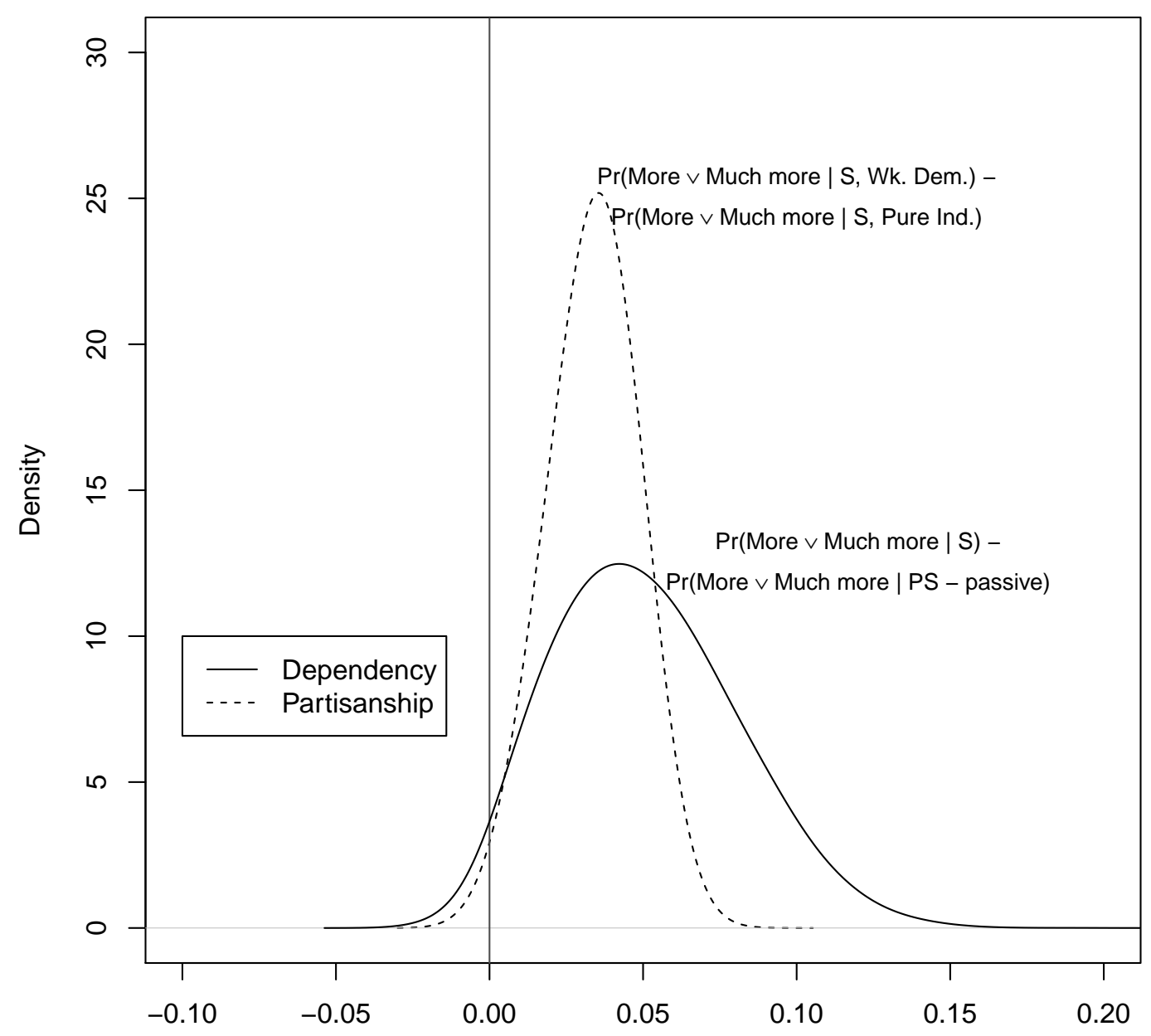

Figure 4: Difference in the predicted probability of supporting "more" or "much more" spending on unemployment benefits. The solid line shows the distribution of the differences in probabilities between two otherwise similar individuals who differ in their dependency statuses. To demonstrate the substantive size of the effect, the dashed line shows the distribution of the predicted differences between two otherwise similar individuals who hold different political views (a "pure" independent and a weakly identifying Democrat, a twopoint shift on the partisanship scale). All other variables in the model were held constant.

For comparison, the plot also includes the estimated difference in support for more unemployment benefits comparing an individual in the dependent role in a single earner household to the individual in the labor force. For the purposes of this comparison, household income is held constant at the average level for single earner households. The estimated difference in probability of support for unemployment benefits is almost indistinguishable from that of 


\section{Effect of Dependency Status on Support for Unemployment Spending}

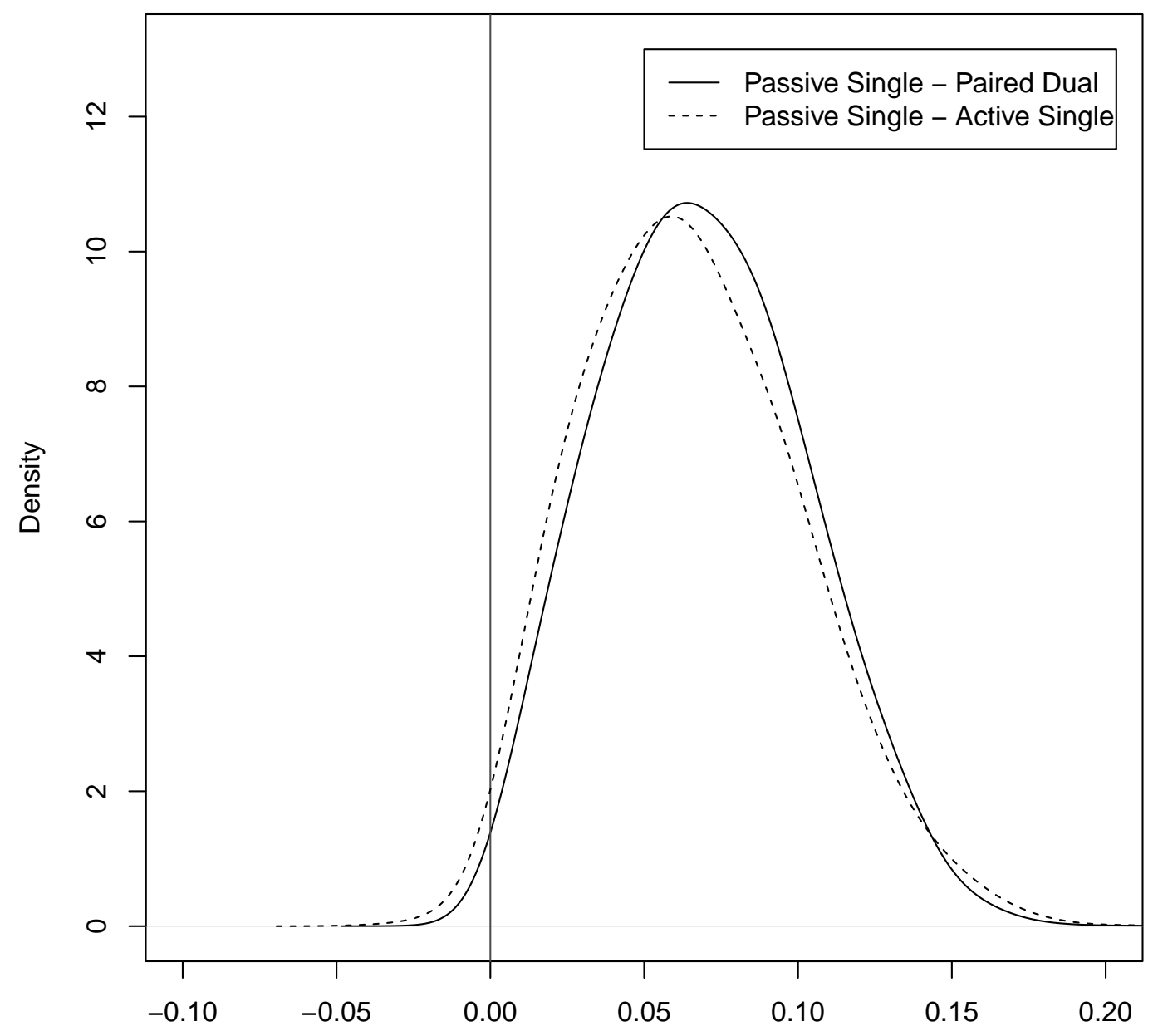

Figure 5: Difference in the predicted probability of supporting "more" or "much more" spending on unemployment benefits. The solid line shows the distribution of the differences in probabilities between two otherwise similar individuals who differ on their dependency status and average income. The plot shows the difference between an individual in a paired single household with the average earnings of a single earner household as the passive participant and an individual in a paired dual household with the average income of two-earner households. The dashed line shows the distribution of the difference between a dependent in a single earner household and a similarly situated individual in a single earner household who is in the labor force. All other variables in the model were held constant.

the dual-earner comparison.

In sum, we find evidence that our lab findings relating asymmetric dependency status to preferences for social insurance are also visible in observational survey data. The effect of 
asymmetric dependency is both consistent and substantively large.

\section{Conclusion}

Much of the literature on the political economy of the welfare state assumes atomistic individuals, ignoring the ties of mutual and often asymmetric economic dependency that bind us together in households. While evidence from psychology, marketing, and behavioral economics suggests that dependency relationships should matter for how individuals and households approach risky choices and form preferences for insurance, such insights have not been explored in a political context. This paper represents a first step toward integrating these literatures, focusing on a core policy domain: partial insurance against job loss.

We report the results of a laboratory experiment designed to directly investigate whether dependency on another for income in risky circumstances affects people's support for social insurance policies. Unlike previous research, our experiment explicitly removes any redistributive considerations. We viewed our treatment as quite weak, posing a strong test for the existence of any dependency effect. Our most novel finding is that asymmetric dependencybeing dependent on someone else for income when they are not dependent on you-increased subjects' willingness to support income insurance policies, at least when the risk of job loss is not too high. Mutual dependency did not appear to induce any behavior different from what we observe from single individuals. In an effort to demonstrate that these findings are in fact relevant outside our highly stylized lab setting we took our main results to observational survey data from the United States. While such findings are not causally identified we do find additional evidence that closely mirrored what we observed in the more controlled (and contrived) lab environment: asymmetric dependency, i.e., those dependent on others for their well-being are more supportive of unemployment insurance once we condition on a variety of other known covariates.

Two important caveats are in order. First, our weak (non-)finding of any mutual dependency effect in the lab may be due to the fact that we failed to induce a strong enough bond between partners. Future work might explore different ways of increasing the solidarity in pairs by, e.g., using a sample of real-life couples, allowing communication, showing an image of the partner, or simply giving the pairs a name or identity around which to coordinate. Second, we did not explore whether within-subjects changes in dependency status changed subjects' views toward social insurance, again an obvious extension for future work.

Our findings leave the question of mechanisms unresolved. What are the psychological, social, or other processes that give rise to this asymmetry in dependency effects? We can only speculate at this point. For example, we could be observing an "agency effect" where those lacking some semblance of control over the generation of their money income are more supportive of insurance. Or asymmetric dependency could induce feelings of vulnerability. If either reaction exists, how permanent or transitory is it? Other mechanisms are surely possible and future work is needed.

Another open question relating to mechanisms is the extent to which our findings travel to different national and cultural contexts. All our data and subjects were drawn from the 
United States. It may be that people with exposure to different gender norms, unemployment insurance policies, or "varieties of capitalism" may react differently. For example, countries where publicly provided services (such as health care) are widespread and not means-tested may see a less pronounced asymmetry effect.

Historically, the vast majority of asymmetrically dependent individuals have been women in homemaker and caretaker roles. In our lab study all interactions were anonymous, instructions were gender-neutral, and partnerships could not be dissolved. We abstracted away from gender roles in dependency relationships yet we still found that dependency matters. Moreover, in our experiment we found no significant gender gap in support for social insurance. In the survey data we found that gender is not a significant predictor of support for social insurance once we accounted for dependency status. It appears that individuals' policy preferences respond to local, relationship-specific dependency in addition to broader gendered differences in labor force opportunities and public policy.

Finally, our findings have an important implication for observational studies: if the asymmetric dependency result is stable and consistent then we should observe important spatial and diachronic variation in the support for social insurance as women entered the labor force in greater numbers and marital stability fluctuated.

\section{References}

Abdellaoui, M., O. l'Haridon, and C. Paraschiv (2013). Individual vs. couple behavior: an experimental investigation of risk preferences. Theory and Decision 75(2), 175-191.

Agranov, M. and T. R. Palfrey (2014, February). Equilibrium tax rates and income redistribution: A laboratory study. Working Paper 19918, National Bureau of Economic Research.

Almås, I., A. W. Cappelen, E. Sorensen, and B. Tungodden (2010). Fairness and the development of inequality acceptance. Science 328(5982), 1176-1178.

Anderson, D. R. and J. R. Nevin (1975). Determinants of young marrieds' life insurance purchasing behavior: An empirical investigation. The Journal of Risk and Insurance 42 (3), pp. 375-387.

Ashraf, N. (2009). Spousal control and intra-household decision making: An experimental study in the philippines. The American Economic Review 99(4), pp. 1245-1277.

Bagozzi, R. P. (2012). Alternative approaches for thinking about and modeling consumer decisions in relationships. Journal of Consumer Psychology 22(3), 315 - 319.

Barber, B., P. Beramendi, and E. Wibbels (2013). The behavioral foundations of social politics: evidence from surveys and a laboratory experiment. Comparative Political Studies 46(10), 1155-89. 
Bateman, I. and A. Munro (2005). An experiment on risky choice amongst households. The Economic Journal 115(502), C176-C189.

Bateman, I. and A. Munro (2013). Testing economic models of the household: An experiment. Technical report, CSERGE Working Paper EDM, No. 04-01.

Bellante, D. and C. A. Green (2004). Relative risk aversion among the elderly. Review of Financial Economics 13, 269-81.

Belot, M., R. Duch, and L. Miller (2015). A comprehensive comparison of students and non-students in classic experimental games. Journal of Economic Behavior \& Organization 113, 26-33.

Bertocchi, G., M. Brunetti, and C. Torricelli (2010). Marriage and other risky assets: A portfolio approach. CEPR Discussion Papers (DP7162).

Bogach, O., L. Lefgren, and D. Sims (2013). Did you build that? effort, luck, and voting for redistribution.

Bolton, G. E. and A. Ockenfels (2000). Erc: A theory of equity, reciprocity, and competition. The American Economic Review 90(1), pp. 166-193.

Bone, J., J. Hey, and J. Suckling (1999). Are groups more or less consistent than individuals? Journal of Risk and Uncertainty 8, 63-81.

Braaten, R. H. and P. Martinsson (2015). Experimental measures of household decision power.

Burden, B. C. (2008). The social roots of the partisan gender gap. Public Opinion Quarterly $72(1), 55-75$.

Cabrales, A., R. Nagel, and J. RodrguezMora (2012). It is hobbes, not rousseau: an experiment on voting and redistribution. Experimental Economics 15(2), 278-308.

Carlsson, F., P. Martinsson, P. Qin, and M. Sutter (2013). The influence of spouses on household decision making under risk: an experiment in rural china. Experimental Economics 16(3), 383-401.

Charness, G. and M. Rabin (2002). Understanding social preferences with simple tests. The Quarterly Journal of Economics 117(3), pp. 817-869.

Chen, Y. and S. X. Li (2009). Group identity and social preferences. The American Economic Review 99(1), pp. 431-457.

Clarke, D. and G. Kalani (2011). Insurance Design for Developing Countries, Chapter Microinsurance decisions: evidence from Ethiopia. Oxford: University of Oxford. 
de Palma, A., N. Picard, and A. Ziegelmeyer (2011). Individual and couple decision behavior under risk: evidence on the dynamics of power balance. Theory and Decision 70 (1), 45-64.

Drewianka, S. (2008). Household production and risk-aversion.

Edlund, L. and R. Pande (2002). Why have women become left-wing? the political gender gap and the decline in marriage. The Quarterly Journal of Economics 117(3), pp. 917-961.

Esarey, J., T. C. Salmon, and C. Barrilleaux (2011a). Social insurance and income redistribution in a laboratory experiment. Political Research Quarterly 65(3), 685-98.

Esarey, J., T. C. Salmon, and C. Barrilleaux (2011b). What motivates political preferences? self-interest, ideology, and fairness in a laboratory democracy. Economic Inquiry.

Falk, A. and U. Fischbacher (2006). A theory of reciprocity. Games and Economic Behavior $54(2), 293-315$.

Fehr, E. and K. M. Schmidt (1999). A theory of fairness, competition, and cooperation. The Quarterly Journal of Economics 114(3), pp. 817-868.

Ferber, R. and L. C. Lee (1980). Acquisition and accumulation of life insurance in early married life. The Journal of Risk and Insurance 47(4), pp. 713-734.

Finseraas, H., N. Jakobsson, and A. Kotsadam (2012). The gender gap in political preferences: An empirical test of a political economy explanation. Social Politics: International Studies in Gender, State \& Society 19(2), 219-242.

Fischbacher, U. (2007). z-tree: Zurich toolbox for ready-made economic experiments. Experimental Economics 10(2), 171-8.

Fortin, B. and G. Lacroix (1997). A test of the unitary and collective models of houselhold labour supply. The Economic Journal 107(443), 933-955.

Gill, D. and V. Prowse (2011). A novel computerized real effort task based on sliders. discussion papers IZA DP no. 5801, Institute for the Study of Labor (IZA).

Gill, D. and V. Prowse (2012). A structural analysis of disappointment aversion in a real effort competition. American Economic Review 102(1), 469-503.

Goldsmith, A. (1983). Household life cycle protection: Human capital versus life insurance. The Journal of Risk and Insurance 50(3), pp. 473-486.

Gorlin, M. and R. Dhar (2012). Bridging the gap between joint and individual decisions: Deconstructing preferences in relationships. Journal of Consumer Psychology 22(3), 320 -323 .

Gray, J. S. (1998). Divorce-law changes, household bargaining, and married women's labor supply. The American Economic Review 88(3), pp. 628-642. 
Greiner, B. (2004). Forschung und wissenschaftliches rechnen. Volume 63, Chapter An online recruitment system for economic experiments, pp. 79-93. Göttingen: Ges. für Wiss. Datenverarbeitung: Elsevier.

Hall, P. and D. Soskice (Eds.) (2001). Varieties of Capitalism. Oxford: Oxford University Press.

Hamilton, R. W. and G. J. Biehal (2005). Achieving your goals or protecting their future? the effects of self?view on goals and choices. Journal of Consumer Research 32(2), pp. $277-283$.

Higgins, T. (1998). Promotion and prevention: Regulatory focus as a motivational principle. In M. P. Zanna (Ed.), Advances in Experimental Social Psychology, pp. 1-46. Princeton: Academic Press.

Hopper, J. S. (1995). Family financial decision making: implications for marketing strategy. Journal of Services Marketing 9(1), 24-32.

Hotz, V. J., E. Peet, and D. Thomas (2013). Household decision-making: The efficiency of resource allocations in indonesian households. Technical report, Duke University.

Howard, C. (2008). The Welfare State Nobody Knows: Debunking Myths about U.S. Social Policy. Princeton: Princeton University Press.

Iversen, T. and F. Rosenbluth (2006). The political economy of gender: Explaining crossnational variation in household bargaining, divorce, and the gender voting gap. American Journal of Political Science 50(1), 1-19.

Iversen, T. and F. Rosenbluth (2010). Women, Work, and Politics. New Haven: Yale University Press.

Iversen, T. and D. Soskice (2001). An asset theory of social policy preferences. American Political Science Review 95(4), 875-893.

Klor, E. F. and M. Shayo (2010). Social identity and preferences over redistribution. Journal of Public Economics 94 (34), 269 - 278.

Lee, A., J. Aaker, and W. Gardner (2000). The pleasures and pains of distinct self-construals: The role of interdependence in regulatory focus. Journal of Personality and Social Psychology 78(6), pp. 1122-1134.

Lowery, D., M. de Jong, C. J. van Eijk, and S. Taal (2013). Partisan differences in spending preferences after thenew democrat and new labour transformations of party images. Journal of Political Science and Public Affairs 1.

Lundberg, S. and R. A. Pollak (1996). Bargaining and distribution in marriage. The Journal of Economic Perspectives 10(4), pp. 139-158. 
Lundberg, S. J., R. A. Pollak, and T. J. Wales (1997). Do husbands and wives pool their resources? evidence from the united kingdom child benefit. The Journal of Human Resources 32(3), pp. 463-480.

Mandel, N. (2003). Shifting selves and decision making: The effects of self-construal priming on consumer risk-taking. Journal of Consumer Research 30(1), pp. 30-40.

Margalit, Y. (2013). Explaining social policy preferences: Evidence from the great recession. American Political Science Review 107(1), 80-103.

McCarty, N. and J. Pontusson (2011). The political economy of inequality and redistribution. In B. Nolan, W. Salverda, and T. M. Smeeding (Eds.), The Oxford Handbook of Economic Inequality. Oxford University Press.

Meltzer, A. and S. Richard (1981). Rational theory of the size of government. Journal of Political Economy 101(49-83).

Moene, K. O. and M. Wallerstein (2001). Inequality, social insurance, and redistribution. American Political Science Review 95(4), 859-74.

Moene, K. O. and M. Wallerstein (2003). Earnings inequality and welfare spending. World Politics 55, 485-516.

Munro, A., I. Bateman, and T. McNally (2013). The family under the microscope: an experiment testing economic models of household choice. Technical report, MPRA Working Paper No. 8974.

Nickelsburg, J. and J. F. Timmons (2012). On the (ir)relevance of skill specificity for social insurance. Quarterly Journal of Political Science 7, 35-67.

Rabin, M. (1993). Incorporating fairness into game theory and economics. The American Economic Review 83(5), pp. 1281-1302.

Rehm, P. (2009). Risks and redistribution: An individual-level analysis. Comparative Political Studies 42(7), 855-881.

Rehm, P. (2011). Social policy by popular demand. World Politics 63(2), 271-299.

Rutstrom, E. E. and M. B. Williams (2000). Entitlements and fairness: an experimental study of distributive preferences. Journal of Economic Behavior 83 Organization 43(1), $75-89$.

Scheve, K. and D. Stasavage (2006). Religion and preferences for social insurance. Quarterly Journal of Political Science 1, 255-86.

Scheve, K. and D. Stasavage (2008). Religion and social insurance: Evidence from the united states, 1970-2002. In I. Shapiro, P. Swenson, and D. Donno (Eds.), Divide and deal : the politics of distribution in democracies, pp. 149-85. New York University Press. 
Simpson, J. A., V. Griskevicius, and A. J. Rothman (2012). Consumer decisions in relationships. Journal of Consumer Psychology 22(3), $304-314$.

Sundn, A. E. and B. J. Surette (1998). Gender differences in the allocation of assets in retirement savings plans. American Economic Review, Papers 83 Proceedings 88, 207-11.

Zhou, R. and M. T. Pham (2004). Promotion and prevention across mental accounts: When financial products dictate consumers investment goals. Journal of Consumer Research 31(1), pp. 125-135.

Zietz, E. N. (2003). An examination of the demand for life insurance. Risk Management and Insurance Review 6(2), 159-191. 